Alaa H. Ali

BDS, (Master student)

Abduladheem Raouf Sulaiman BDS, MSc, PhD. (Lec.)

\section{The Effect of Diode Laser Irradiation on Surface Roughness of Bleached Enamel: An in Vitro Study}

\author{
Department of Conservative Dentistry \\ College of Dentistry, University of Mosul \\ Department of Conservative Dentistry \\ College of Dentistry, University of Mosul
}

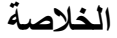

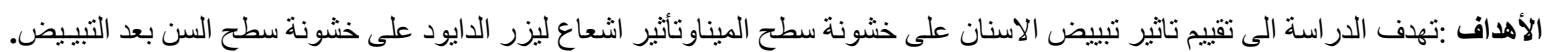

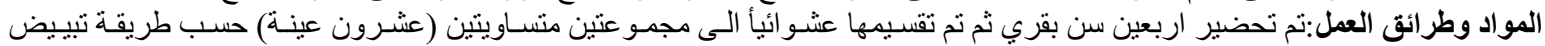

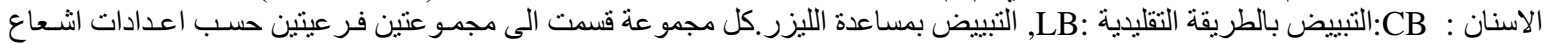

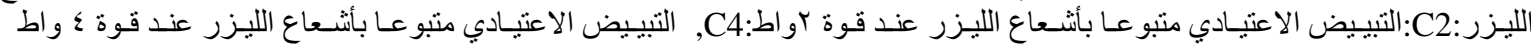

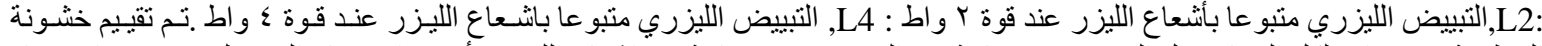

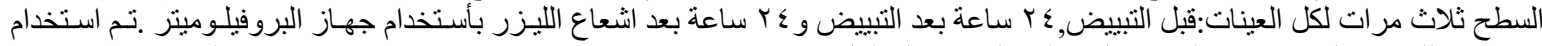

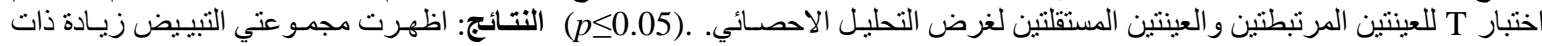

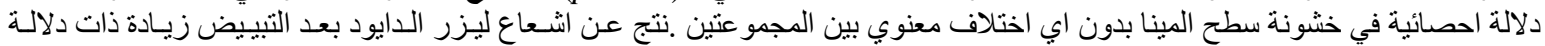

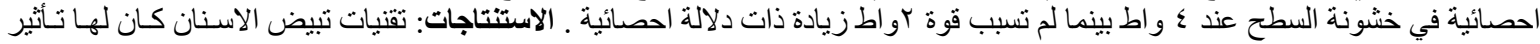

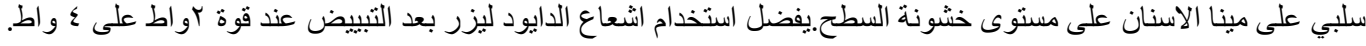

\begin{abstract}
Aims: To evaluate the influence of post bleaching diode laser irradiation on the surface roughness of bleached enamel. Materials and methods: Forty bovine teeth were prepared and then randomly divided into two equal groups $(n=20)$ according to the in-office bleaching technique as follows: CB: Conventional in-office bleaching technique LB: Laser-assisted in-office bleaching technique. Each group was then subdivided into two subgroups ( $\mathrm{n}=10)$ according to laser irradiation setting as follows: $\mathrm{C} 2$ : Conventionally bleached followed by 2-Watt laser irradiation, C4: Conventionally bleached followed by 4-Watt laser irradiation, L2: Laser-assisted bleached followed by $2 \mathrm{Watt}$ laser irradiation and L4: Laser-assisted bleached followed by 4 Watt laser irradiation. Surface roughness was assessed three times for all the specimens: before bleaching, 24 hours after bleaching and finally 24 hours after post bleaching diode laser irradiation by utilizing profilometer. Paired samples $t-$ test and independent samples $t-$ test was utilized for statistical analysis at $p \leq 0.05$. Results: Both bleached groups exhibited a significant increase in the surface roughness of enamel with no statistically significant difference between them. Post bleaching diode laser irradiation at 4Watt resulted in a significant increase in surface roughness of enamel, while 2 Watt diode laser irradiation resulted in non-significant increase in surface roughness of enamel. Conclusions: In-office bleaching techniques had a negative impact on enam$\mathrm{el}$ in terms of surface roughness. Post bleaching diode laser irradiation at $2 \mathrm{Watt}$ power parameter is more preferred than 4Watt power parameter.

Keywords: Diode laser irradiation, Surface roughness, Conventional in-office bleaching, laser-assisted inoffice bleaching
\end{abstract}

The Effect of Diode Laser Irradiation on Surface Roughness of Bleached Enamel: An in Vitro Study. AlRafidain Dent J. 2021; 21(2):202-214.

DOI: $10.33899 /$ rdenj.2021.169253 C2020, College of Dentistry, University of Mosul.

Received: $1 / 12 / 2020$

Sent to Referees: 5/12/2020

Accepted for Publication: 14/1/2021

This is an open access article under the CC BY 4.0 license (http://creativecommons.org/licenses/by/4.0/). 


\section{INTRODUCTION}

Growth in patient's awareness about esthetics caused an increase in the popularity of dental bleaching procedure. It can be classified generally into two basic types: In-office dental bleaching procedure, which is accomplished by the dental professional at dental clinics and at-home dental bleaching procedure in which the patient himself applies the bleaching material into custom made tray that fits his teeth at home and under the supervision of the dental professionals ${ }^{(1)}$. The in-office dental bleaching technique is carried out by using higher concentrations of bleaching agent $(35 \%-38 \%$ carbamide peroxide or $25 \%-40 \%$ hydrogen peroxide) for short duration of bleaching time, while lower concentrations of bleaching agent (10\%-16\% carbamide peroxide or 3\%-6 $\%$ hydrogen peroxide) are utilized in athome bleaching technique for long duration $^{(1)}$.

The precise mechanism of tooth bleaching is not completely understood, but it can be attributed to the changes that may occur in the chemical structures of tooth by free radicals that are released as a result of hydrogen peroxide decomposition by oxidation reduction reactions ${ }^{(2)}$. These free radicals are considered as extremely unstable agents because they have in their outer orbital one or more unpaired electron (3). They have great tendency to acquire electron from adjacent compounds for stabilization of their molecular structure. As consequence, the pigmented molecules within the dental structure become oxidized leading to decrease or elimination of tooth discoloration ${ }^{(3)}$.

A relatively new advancement in the field of in-office dental bleaching technique is the activation of bleaching agent by laser light by incorporating specific chromophores in bleaching material that are capable of absorbing specific wavelength of laser ${ }^{(4)}$. Although the efficacy of dental bleaching in improving the color of teeth is not questioned ${ }^{(5-8)}$, there is a controversy with no general agreement about the safety of dental bleaching on surface roughness of enamel ${ }^{(7,9)}$. A wide range of lasers has been utilized as post bleaching treatment modalities in an attempt to enhance the microhardness of bleached enamel, which could be explained by some chemical and physical alterations in enamel structures caused by photochemical or photothermal interactions induced by laser (10). Different effects were found depending on the temperature degree reached during laser irradiation treatment ${ }^{(11)}$. The evidence in literature is very rare regarding the application of diode laser irradiation on bleached enamel and to the best of our knowledge there are limited studies investigated its effect on of enamel ${ }^{(12)}$ with no previous study assessed its effect on surface roughness of bleached enamel. Thus, the aim beyond the current study was to assess the effect of in-office bleaching techniques on surface roughness of enamel and the possible influence of post bleaching diode laser irradiation at two power 
parameters on surface roughness of bleached enamel by two different in-office bleaching techniques. The first null hypothesis to be tested was that in-office dental bleaching techniques had no effect on surface roughness of bleached enamel. While the second null hypothesis was that post bleaching diode laser irradiation at two different power parameters had no effect on the surface roughness of enamel.

\section{MATERIALS AND METHODS}

\section{Specimen's collection and preparation}

Forty permanent bovine incisors ${ }^{(13)}$ were utilized in the present study. They were extracted by one of the investigators on the same day of cattle slaughtering to prevent the need for refrigeration and to avoid dehydration of teeth at the same time then they were stored in $0.1 \%$ thymol solution at room temperature for disinfection for one month before starting the study ${ }^{(14)}$. The remnant of soft tissues from the teeth was gently removed by using dental hand scaler. They were examined under stereo microscope (X40) to ensure that the specimens were free from caries, surface cracks or any enamel defect ${ }^{(15)}$. The samples were polished by nonfluoridated pumice (Bilkim LTD/ Turkey) then the roots were cut by utilizing diamond disc with copious water cooling at the level of cement- enamel junction and then the roots were discarded. The crowns were examined again under stereo microscope to exclude any sample with exposed dentin. The crowns were embedded in cold cure acrylic resin in custom made Poly Venile Chloride (PVC) rings with their labial surface facing upward. The samples were wet sanded by using ascending grit water proof silicon carbide papers (King spor/ Germany) started from \#400 up to $\# 1,200$ under running water for a total of 25 seconds ( 5 second/ grit). The specimens were placed in ultrasonic bath (Biosonic UC50DB, Coltene whaledent/ USA) to remove all the impurities for 15 minutes (7). The center of the labial surface was chosen to conduct the study ${ }^{(13)}$. The target area was defined by using masking tape with $5 \mathrm{~mm}$ diameter hole to standardize the area of measurements. The samples were stored in deionized water during conducting the study.

\section{Study design and specimens grouping}

Forty bovine teeth were randomly allocated into two groups $(n=20)$ according to bleaching technique being used as follows:

CB group: Conventional in-office bleaching technique was performed by utilizing 35\% hydrogen peroxide (Quick White in surgery bleaching kit/ UK). According to the manufacturer instructions, the hydrogen peroxide liquid was mixed with powder until thick homogenous mixture was obtained. A uniform layer of $2 \mathrm{~mm}$ thickness was applied to the target area and left for 10 minutes and considered as one treatment cycle then rinsed, dried and the treatment cycle was repeated two more 
times. Total bleaching time was 30 minutes.

LB group: Laser assisted in-office technique was accomplished by using Laser white 20 whitening gel kit (Biolase, Irvine/ California, USA). According to the manufacturer instructions, the activator gel syringe and base gel syringe were connected after that the base gel (clear content) was transferred to the activator gel syringe (purple content) then this action was repeated 25 times to assure the complete mixing of both gels and homogenous lavender colored mixture was yielded. The concentration of hydrogen peroxide in the resulted gel was $35 \%$. The specimens were arranged so that every 4 specimens were bleached at the same time to simulate the 4 quadrants of the patient's mouth to follow the manufacturer instructions strictly (Figure 1). A uniform layer of resulted bleaching gel (about $1 \mathrm{~mm}$ thickness) was applied on the four specimens. After the disposable protective shield was placed on the whitening hand piece of the diode laser device with 940 nanometer (Epic 10, Bio- lase, Irvine/ California, USA), the hand piece was placed perpendicular and in close proximity to the bleaching gel of one specimen without being in contact with it. Each tooth of the four teeth were subjected separately to a preset whitening mode (continuous wave mode, 7 Watt) for 30 seconds resulting in a total resting time of 1.5 minutes for each tooth (which is the time required to lase the remaining three teeth). This procedure was repeated twice which produced a total time of 1 minute laser exposure and 3 minutes of rest (without laser irradiation) for each tooth. According to the manufacturer instructions, the bleaching gel was allowed to remain on the teeth for 5 minutes after the second laser exposure. After that the bleaching gel was suctioned and teeth rinsed with deionized water. All of the above mentioned procedure was considered as one bleaching cycle that was repeated again. The total bleaching time after two bleaching cycles was 18 minutes with 2 minutes of laser activation for each specimen.

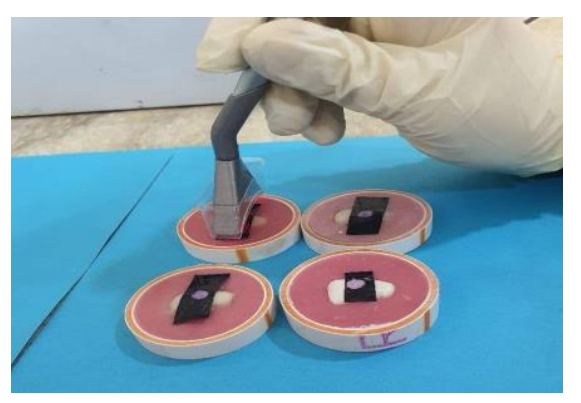

Figure (1): Samples arrangement during laser-assisted in-office bleaching.

\section{Post bleaching diode laser irradiation}

Both conventionally and laser assisted inoffice bleaching groups were subdivided into two subgroups according to diode laser irradiation setting that it was received after bleaching as follows: 
C2: Conventionally bleached followed by diode laser irradiation at $2 \mathrm{Watt}$ power parameter.

C4: Conventionally bleached followed by diode laser irradiation at 4 Watt power parameter.

L2: Laser bleached followed by diode laser irradiation at $2 \mathrm{Watt}$ power parameter.

L4: Laser bleached followed by diode laser irradiation at $4 \mathrm{Watt}$ power parameter. Forty-eight hours after dental bleaching, all the specimens were irradiated by a diode laser device (Epic 10, Biolase, Irvine/ California, USA), the same diode laser device that was previously used for the activation of the aforementioned bleaching gel. The energy of the laser was transmitted via the optical fiber delivery system (EZ tips, Biolase, Irvine/ California, USA) with $400 \mu \mathrm{m}$ in diameter and $4 \mathrm{~mm}$ length. The tip of the laser was positioned in non- contact mode with a standard distance of 1 $\mathrm{mm}$ from the enamel surface. For standardization of the distance and perpendicularity of the laser tip, a milling machine (Bio art $1000 \mathrm{Ma} / \mathrm{Brazil}$ ) was used to stabilize the laser hand piece with the aid of condensation silicone impression material (DUROSIL L/ Germany) which permitted only the horizontal movement of the laser hand piece during the irradiation to ensure that all the specimens were lased in similar manner (Figure 2). The laser irradiation was performed at $2 \mathrm{Watt}$ power parameter for (C2 and L2 groups) and at 4Watt for (C4 and L4 groups) with continuous wave mode. The irradiation time was 15 seconds (12) during which the treatment area was irradiated for three times during the 15 seconds period with uniform scanning motion over the entire target area in incisocervical direction.

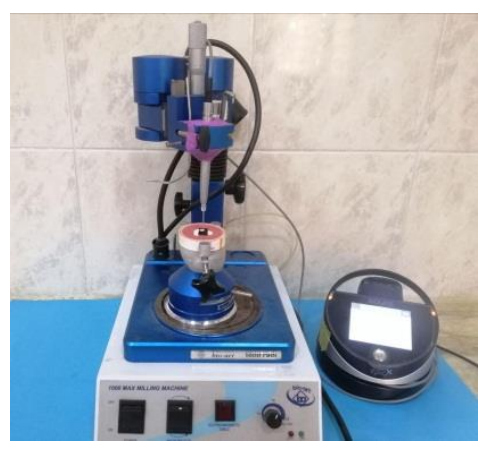

Figure (2): Diode laser hand piece stabilized by milling machine.

\section{Surface roughness assessment}

Three readings per each specimen were performed in different directions (horizontal, vertical and oblique) through the target area passing through the center point of the area ${ }^{(7)}$ by using profilometer (Taylorhobson, tylasurf 10/ Leicester, England), which was equipped with diamond stylus. The evaluation length was fixed at 1.25 $\mathrm{mm}$ with $0.25 \mathrm{~mm}$ cutoff ${ }^{(7)}$. The horizontal magnification was $10000 \mathrm{X}$; while the vertical magnification was $0.25 \mathrm{X}$ during the measurement. The average of three readings was calculated using the arithmetic 
roughness $(\mathrm{Ra})$ parameter and expressed in Micrometer $(\mu \mathrm{m})$. The surface roughness was evaluated before (baseline), 24 hours after dental bleaching and finally 24 hours after post bleaching diode laser irradiation.

\section{Statistical analysis}

The normal distribution of data was verified by performing a normality test (Shapiro- Wilk). All the data showed normal distribution. Therefore, paired samples $t$-test and independent samples $t$-test were performed to compare between before and after treatment and between groups respectively. The significance level was set at $5 \%$ for all tests.

\section{RESULTS}

The data in Table (1) and Figure (3) show the findings of $t$-tests for surface roughness assessment of conventionally and laser assisted bleached groups. Conventional bleaching and laser assisted bleaching techniques resulted in a significant increase in surface roughness of enamel from $(0.127 \pm 0.028$ and $0.122 \pm$
$0.018)$ to $(0.147 \pm 0.20$ and $0.152 \pm 0.026)$ respectively. No significant difference was shown between bleached groups $(P=0.645)$. Post bleaching diode laser irradiation resulted in an increase in Ra value of conventional bleached enamel after 2Watt and 4Watt from (0.139 and 0.155) to $(0.163$ and 0.178$)$ respectively. However, 2Watt power parameter resulted in non-significant increase in surface roughness $(P=0.106)$, whereas, a significant increase was evident after laser irradiation at 4 Watt power parameter $(P=0.014)$ (Table 2) (Figure 4). Similarly, Post bleaching diode laser irradiation at $2 \mathrm{Watt}$ power parameter caused no significant increase in Ra value of laser-assisted bleached enamel $(P=0.056)$. While a significant increase in Ra value was evident after post bleaching diode laser irradiation at $4 \mathrm{Watt}$ power parameter $(P=0.038)$ as shown in Table (3) and Figure (5).

Table (1): Paired samples $t$-test and independent samples $t$ - test for Ra value $(\mu \mathrm{m})$ of conventionally and laser-assisted bleached groups.

\begin{tabular}{ccccc}
\hline Groups & Descriptive statistics & Baseline & Bleached & $\boldsymbol{P}^{\mathbf{a}}$ \\
\hline CB. & Mean \pm SD & $0.127 \pm 0.028$ & $0.147 \pm 0.20$ & $0.001^{*}$ \\
LB. & Mean \pm SD & $0.122 \pm 0.018$ & $0.152 \pm 0.026$ & $0.000^{*}$ \\
\hline $\boldsymbol{P}^{\mathbf{b}}$ & & $0.631^{\times}$ & $0.645^{\times}$ & \\
\hline
\end{tabular}

CB: Conventional bleaching; LB: Laser-assisted bleaching; SD: Standard deviation; $\boldsymbol{P}^{\mathrm{a}}$ : Based on paired samples $t$-test; $\boldsymbol{P}^{\mathbf{b}}$ : Based on independent samples $t$-test.

*indicates a significant difference at $P \leq 0.05$.

${ }^{\times}$indicates non-significant difference at $P>0.05$. 


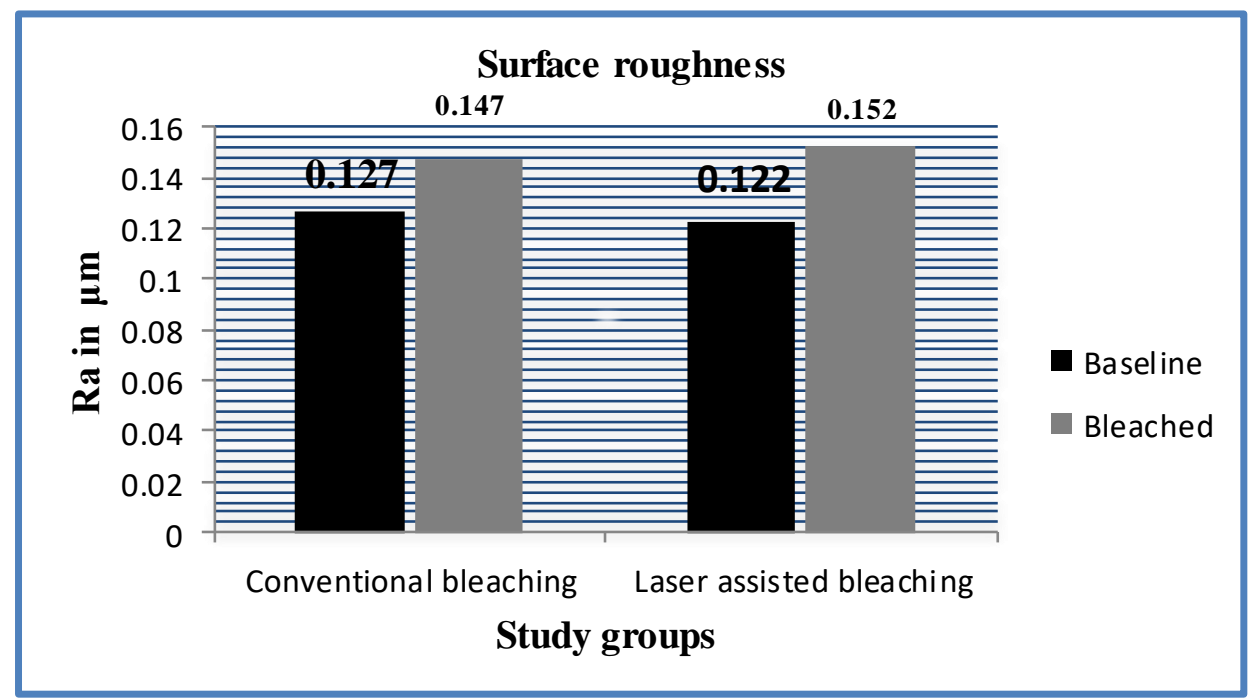

Figure (3): Bar chart represents the Ra values of conventionally and laser-assisted bleached groups.

Table (2): Paired samples $t$-test for Ra value $(\mu \mathrm{m})$ for conventionally bleached groups irradiated after bleaching with laser at two different power parameters.

\begin{tabular}{lllll}
\hline Groups & Descriptive statistics & Bleached & Lased & $P$ \\
\hline C2 & Mean \pm SD & $0.139 \pm 0.021$ & $0.163 \pm 0.013$ & $0.106^{\times}$ \\
C4 & Mean \pm SD & $0.155 \pm 0.018$ & $0.178 \pm 0.030$ & $0.014^{*}$ \\
\hline
\end{tabular}

C2: Laser irradiated group at 2 Watt; C4: Laser irradiated group at 4Watt; SD: Standard deviation; $\boldsymbol{P}$ : Based on paired samples $t$-test.

*indicates a significant difference at $P \leq 0.05$.

$\times$ indicates non-significant difference at $P>0.05$.

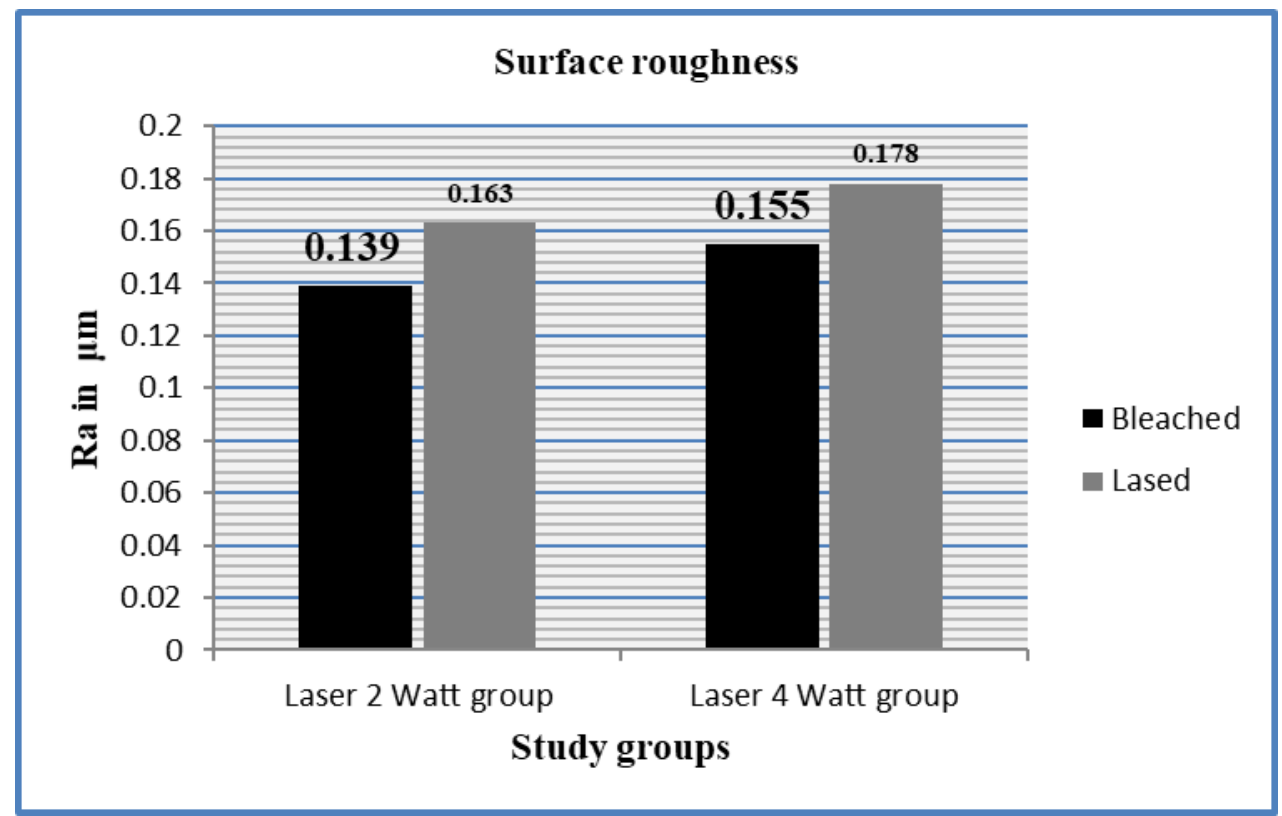

Figure (4): Bar chart represents the Ra value for conventionally bleached groups irradiated after bleaching with laser at two different power parameters. 
Table (3): Paired samples $t$-test for Ra value $(\mu \mathrm{m})$ for laser-assisted bleached groups irradiated after bleaching with laser at two different power parameters.

\begin{tabular}{lllll}
\hline Groups & Descriptive statistics & Bleached & Lased & $P$ \\
\hline L2 & Mean \pm SD & $0.154 \pm 0.024$ & $0.166 \pm 0.019$ & $0.056^{\times}$ \\
L4 & Mean \pm SD & $0.149 \pm 0.029$ & $0.187 \pm 0.039$ & $0.038^{*}$ \\
\hline
\end{tabular}

L2: Laser irradiated group at 2 Watt; L4: Laser irradiated group at 4Watt; SD: Standard deviation; $\boldsymbol{P}$ : Based on paired samples t-test. *Indicates a significant difference at $P \leq 0.05$.

$\times$ indicates non-significant difference at $P>0.05$.

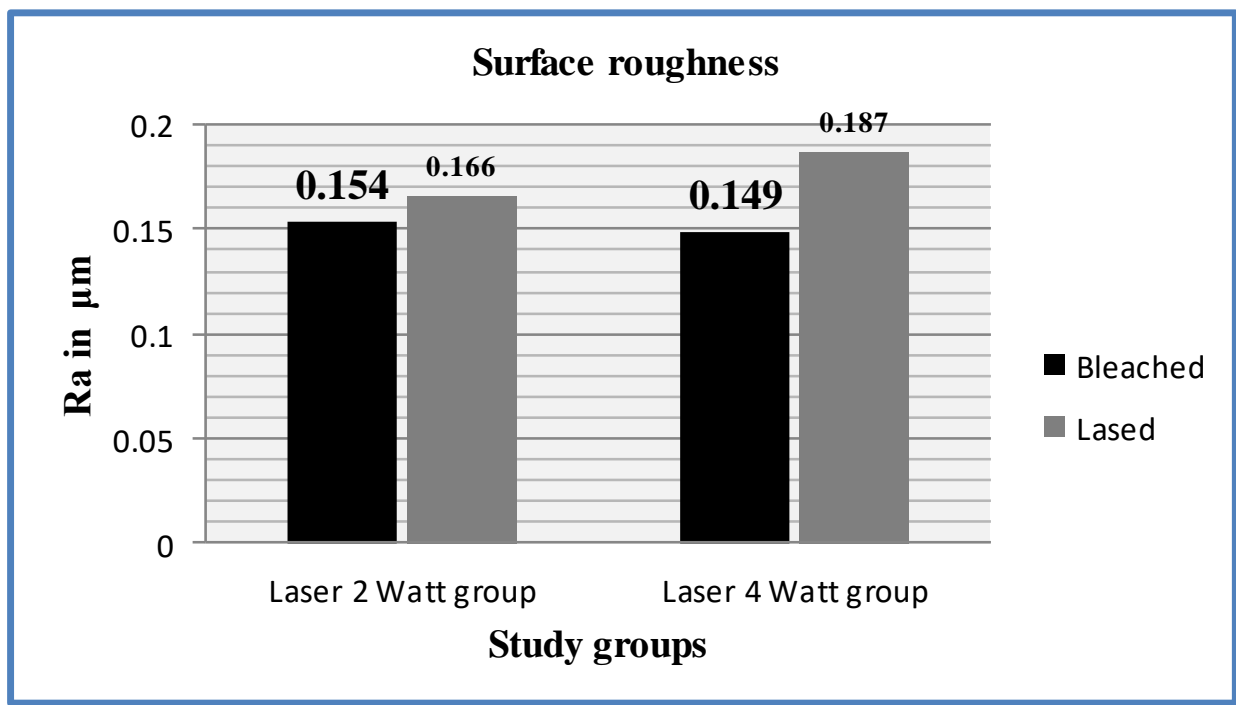

Figure (5): Bar chart represents the Ra value for laser-assisted bleached groups irradiated after bleaching with laser at two different power parameters. 


\section{DISCUSSION}

Dental bleaching procedure is considered as efficient and relatively safe ${ }^{(16)}$. However, some harmful effect could be resulted from this procedure ${ }^{(17)}$. Bovine teeth were used in the present study because of increasing difficulty in obtaining large number of human anterior teeth for dental research with lack of the control of their age as compared to the cows that have the same nutritional condition and slaughtered within the same age range (2-3 years). Furthermore, the infection hazards and ethical issues must be considered ${ }^{(18)}$. Bovine teeth would not be subjected to any previous manufactured fluoride products that may affect the microhardness of enamel which is fundamental in this kind of researches for better standardization ${ }^{(19)}$, in addition to significantly larger flat labial surface ${ }^{(18)}$. The bovine teeth have been proposed as human teeth substitute as there was no significant difference between both in terms of microhardness and chemical composition ${ }^{(13)}$. The mean Ra value obtained after conventional bleaching technique was significantly higher than baseline values. This finding coincides with the findings of other researchers that demonstrated a significant rise in surface roughness of enamel using the same $35 \%$ concentration of $\mathrm{H}_{2} \mathrm{O}_{2}{ }^{(7,20)}$. Dionysopoulos et al. (2016) disagreed with our findings by reporting that $40 \% \mathrm{H}_{2} \mathrm{O}_{2}$ alone or with Er,Cr:YSGG laser irradiation did not affect the surface roughness of enamel significantly. These contradictory findings may be explained by the fact that the specimens in the previous cited study were stored in artificial saliva for 10 days before performing surface roughness assessment ${ }^{(9)}$. Laser assisted in- office bleaching technique also resulted in a significant increase in surface roughness of enamel, which is parallel with the outcome of other study utilized the same bleaching gel (Laser white 20 whitening gel kit, Biolase, Irvine, USA) and diode laser activation device (Epic 10, Biolase, Irvine/ California, USA) ${ }^{(8)}$. In this in vitro study, no significant difference was evident between the mean of $\mathrm{Ra}$ value obtained after conventional and laser assisted in- office bleaching techniques. This outcome is in contrary to Anaraki et al. (2014) who found that the conventional bleaching using $40 \% \mathrm{H}_{2} \mathrm{O}_{2}$ caused non-significant increase in the surface roughness of enamel as compared to laser-assisted bleaching utilizing diode laser that caused a significant increase in surface roughness of enamel ${ }^{(21)}$. In contrast, Mirzaie et al. (2016) concluded that the conventional bleaching using $35 \% \quad \mathrm{H}_{2} \mathrm{O}_{2}$ and laser-assisted bleaching with different laser activation systems (diode or Nd: YAG) and with different $\mathrm{H}_{2} \mathrm{O}_{2}$ concentrations $(30 \%$ or $45 \%$ ) caused a significant increase in the surface roughness of enamel and the higher significant increase in the surface roughness was related to the conventional bleaching technique ${ }^{(20)}$. These controversial findings may reflect the diversity in methodological approaches being utilized in above cited studies such as $\mathrm{H}_{2} \mathrm{O}_{2}$ concentration, different bleaching protocol (number of ses- 
sions, duration of treatment) and type of laser activation with different irradiation settings. The increase in the surface roughness of enamel after dental bleaching could be explained by some authors who stated that the dissolution of superficial layer of enamel such as the acquired pellicle and enamel cuticle with disintegration of superficial aprismatic layer of enamel could result in surface roughness increase, which occurred as the effect of bleaching agent on the organic matrix of enamel ${ }^{(22)}$. On the other hand, other researchers confirmed alteration in calcium to phosphate ratio to $10 \mathrm{~nm}$ depth of subsurface enamel when some bleaching techniques were performed. This may cause an increase in inter rod distance with subsequent increase in the surface roughness of enamel ${ }^{(23)}$. The post bleaching diode laser irradiation at 4Watt power parameter caused a significant increase in mean Ra value for both conventionally and laser-assisted bleached enamel. While post bleaching diode laser irradiation at $2 \mathrm{Watt}$ power parameter did not show a significant increase in $\mathrm{Ra}$ value. To the best of our knowledge, there is no previous study investigated the influence of diode laser irradiation on the surface roughness of enamel. This effect may be attributed to the heat accumulation at enamel surface resulted from low absorption of dental enamel to infrared radiation ${ }^{(24)}$. This thermal effect may lead to the creation of micro spaces as consequence of loss of carbonate, water and organic matrix from laser irradiated enamel ${ }^{(25)}$. The energy density of the laser can be calculated as power density multiplied by the total laser irradiation time. Thus the energy density could be increased by increasing the power parameter of diode laser ${ }^{(26)}$. As consequence, the increased energy density could cause higher thermal load of diode laser irradiation ${ }^{(27)}$. This increased energy density could explain the significant increase in enamel surface roughness after diode laser irradiation at $4 \mathrm{~W}$ as compared to non-significant increase in the surface roughness of enamel after diode laser irradiation at $2 \mathrm{~W}$. Further studies are suggested to disclose the exact mechanism of action of diode laser irradiation on enamel surface. The null hypotheses of this in vitro study were rejected as both dental bleaching techniques and post bleaching diode laser irradiation caused significant changes in the surface roughness of enamel.

\section{CONCLUSIONS}

Within the limitations of the present study, laser assisted in-office dental bleaching produced the same increase in the surface roughness of enamel as conventional in-office dental bleaching but within shorter period of bleaching procedure. Post bleaching diode laser irradiation at 2 Watt power is more preferable than 4Watt power parameter in terms of the enamel surface roughness increasing and can be used as post bleaching treatment modality without causing deleterious effect on the surface of enamel in terms of surface roughness. More studies are needed to disclose the clinical sig- 
nificance of post bleaching diode laser irradiation treatment modality.

\section{REFERENCES}

1. White D, Kozak K, Zoladz J, Duschner H, Götz H. Peroxide interactions with hard tissues: effects on surface hardness and surface/subsurface ultrastructural properties. Compend Contin Educ Dent. 2002;23:42-48.

2. Dahl J, Pallesen U. Tooth bleaching-a critical review of the biological aspects. Crit Rev Oral Biol Med. 2003;14:292-294.

3. Minoux M, Serfaty R. Vital tooth bleaching: biologic adverse effects-a review. Quintessence Int. 2008;39:645-659.

4. Wetter N, Barroso M, Pelino J. Dental bleaching efficacy with diode laser and LED irradiation: an in vitro study. Lasers Surg Med. 2004;35(4):254-258.

5. Mushashe A, Coelho B, Garcia P, Rechia B, da Cunha L, Correr, G, Gonzaga C. Effect of different bleaching protocols on whitening efficiency and enamel superficial microhardness. $J$ Clin Exp Dent. 2018;10(8):e772-e775.

6. Grazioli G, Valente L, Isolan C, Pinheiro H, Duarte C, Münchow E. Bleaching and enamel surface interactions resulting from the use of highly-concentrated bleaching gels. Arch Oral Biol. 2018;87:157-162.

7. Vieira I, Vieira-Junior W, Pauli M, Theobaldo J, Aguiar F, Lima D, Leonardi G. Effect of in-office bleaching gels with cal- cium or fluoride on color, roughness, and enamel microhardness. J Clin Exp Dent. 2020;12(2):e116-e122.

8. Ergin E, Yazici A, Kalender B, Usumez A, Ertan A, Gorucu J, Sari T. In vitro comparison of an Er:YAG laser-activated bleaching system with different lightactivated bleaching systems for color change, surface roughness, and enamel bond strength. Lasers Med Sci. 2018;33(9):1913-1918.

9. Dionysopoulos D, Strakas D, KoliniotouKoumpia E, Koumpia E. Effect of Er,Cr:YSGG laser irradiation on bovine enamel surface during in-office tooth bleaching ex vivo. Odontology. 2016;105(3):320-328.

10. de Sant'Anna G, dos Santos E, Soares L, do Espírito Santo A, Martin A, Duarte D. Pacheco-Soares C, Brugnera A. Dental enamel irradiated with infrared diode laser and photo-absorbing cream: part 2--EDX study. Photomed Laser Surg. 2009;27(5):771-782.

11. Holcomb D, Young R. Thermal decomposition of human tooth enamel. Calcif Tissue Int. 1980;31(3):189-201.

12. Moharam L, Sadony D, Nagi S. Evaluation of diode laser application on chemical analysis and surface microhardness of white spots enamel lesions with two remineralizing agents. J Clin Exp Dent. 2020;12(3):e271-e276. 
13. Arango-Santander S, Montoya C, PelaezVargas A, Ossa E. Chemical, structural and mechanical characterization of bovine enamel. Arch Oral Biol. 2020;109:104573.

14. Aydin B, Pamir T, Baltaci A, Orman M, TurK T. Effect of storage solutions on microhardness of crown enamel and dentin. Eur J Dent. 2015; 9(2): 262-266.

15. de Castro Mde F, Silva A, Franco M, Silva A, Bramante Fda S, da Silva M, Lima D, Pereira Ade F. The Effect of 3\% Phosphate Ascorbyl Gel on Bond Strength of Composite Resin to Enamel treated with 35\% Hydrogen Peroxide. J Contemp Dent Pract. 2015; 16(5): 376-382.

16. Li Y. Safety controversies in tooth bleaching. Dent Clin North Am. 2011;55:255263.

17. Li Y, Greenwall L. Safety issues of tooth whitening using peroxide-based materials. Br Dent J. 2013;215:29-34.

18. Yassen G, Platt J, Hara, A. Bovine teeth as substitute for human teeth in dental research: A review of literature. J Oral Sci. 2011;53(3): 273-282.

19. Al-Maliky M, Frentzen M, Meister J. Artificial Caries Resistance in Enamel after Topical Fluoride Treatment and $445 \mathrm{~nm}$ Laser Irradiation. Biomed Res Int. 2019;2019:1-11.

20. Mirzaie M, Yassini E, Ganji S, Moradi Z, Chiniforush N. A Comparative Study of Enamel Surface Roughness after Bleach- ing with Diode Laser and Nd: YAG Laser. J Lasers Med Sci. 2016;7(3):197-200.

21. Anaraki S, Shahabi S, Chiniforush N, Nokhbatolfoghahaei $\mathrm{H}$, Assadian $\mathrm{H}$, Yousefi B. Evaluation of the effects of conventional versus laser bleaching techniques on enamel microroughness. Lasers Med Sci. 2014;30(3):1013-1018.

22. Markovic L, Jordan R, Lakota N, Gaengler P. Micromorphology of enamel surface after vital tooth bleaching. $J$ Endod. 2007;33(5):607-610.

23. Hosoya $\mathrm{N}$, Honda $\mathrm{K}$, Iino $\mathrm{F}$, Arai $\mathrm{T}$. Changes in enamel surface roughness and adhesion of Streptococcus mutans to enamel after vital bleaching. $J$ Dent. 2003;31(8):543-548.

24. Arrastia A, Machida T, Smith P, Matsumoto K. Comparative study of the thermal effects of four semiconductor lasers on the enamel and pulp chamber of a human tooth. Lasers Surg Med. 1994;15: 382 389.

25. Oho T, Morioka T. A possible mechanism of acquired acid resistance of human dental enamel by laser irradiation. Caries Res. 1990;24(2): 86-92.

26. Selting W. (2017). Laser operating parameters for hard and soft tissue, surgical and PBM management. In: Coluzzi D. and Parker S. (eds). Laser in Dentistry- Current Concepts. $1^{\text {st }}$ Edn. Springer International Publishing, Switzerland AG, Gew- 
erbestrasse, Cham, Switzerland; Pp: 5787.

27. Khouja F, Abdelaziz M, Bortolotto T, Krejci I. Intra-pulpal and subsurface tem- perature rise during tooth irradiation with $808 \mathrm{~nm}$ diode laser: an in vitro study. Eur J Paediatr Dent. 2017; 18(1): 56-60. 